\title{
Diazotroph Genomes and Their Seasonal Dynamics in a Stratified Humic Bog Lake
}

\section{Leyden Fernandez ${ }^{1}$, Sari Peura ${ }^{2}$, Alexander Eiler ${ }^{1,3}$, Alexandra M. Linz ${ }^{4}$, Katherine D. McMahon ${ }^{5,6}$ and Stefan Bertilsson ${ }^{1,7 *}$}

\footnotetext{
'Department of Ecology and Genetics, Limnology and Science for Life Laboratory, Uppsala University, Uppsala, Sweden, ${ }^{2}$ Department of Forest Mycology and Plant Pathology, Science for Life Laboratory, Swedish University of Agricultural Sciences, Uppsala, Sweden, ${ }^{3}$ Centre for Biogeochemistry in the Anthropocene, Department of Biosciences, Section for Aquatic Biology and Toxicology, University of Oslo, Oslo, Norway, ${ }^{4}$ Great Lakes Bioenergy Research Center, Wisconsin Energy Institute, University of Wisconsin-Madison, Madison, WI, United States, ${ }^{5}$ Department of Bacteriology, University of Wisconsin-Madison, Madison, WI, United States, ${ }^{6}$ Department of Civil and Environmental Engineering, University of Wisconsin-Madison, Madison, WI, United States, ${ }^{7}$ Department of Aquatic Sciences and Assessment, Swedish University of Agricultural Sciences, Uppsala, Sweden
}

Aquatic $\mathrm{N}$-fixation is generally associated with the growth and mass development of Cyanobacteria in nitrogen-deprived photic zones. However, sequenced genomes and environmental surveys suggest active aquatic $\mathrm{N}$-fixation also by many noncyanobacterial groups. Here, we revealed the seasonal variation and genomic diversity of potential $\mathrm{N}$-fixers in a humic bog lake using metagenomic data and nif gene clusters analysis. Groups with diazotrophic operons were functionally divergent and included Cholorobi, Geobacter, Desulfobacterales, Methylococcales, and Acidobacteria. In addition to nifH (a gene that encodes the dinitrogenase reductase component of the molybdenum nitrogenase), we also identified sequences corresponding to vanadium and iron-only nitrogenase genes. Within the Chlorobi population, the nitrogenase (nifH) cluster was included in a well-structured retrotransposon. Furthermore, the presence of light-harvesting photosynthesis genes implies that anoxygenic photosynthesis may fuel nitrogen fixation under the prevailing low-irradiance conditions. The presence of $r n f$ genes (related to the expression of $\mathrm{H}^{+} / \mathrm{Na}^{+}$-translocating ferredoxin: NAD+ oxidoreductase) in Methylococcales and Desulfobacterales suggests that other energygenerating processes may drive the costly $\mathrm{N}$-fixation in the absence of photosynthesis. The highly reducing environment of the anoxic bottom layer of Trout Bog Lake may thus also provide a suitable niche for active $\mathrm{N}$-fixers and primary producers. While future studies on the activity of these potential $\mathrm{N}$-fixers are needed to clarify their role in freshwater nitrogen cycling, the metagenomic data presented here enabled an initial characterization of previously overlooked diazotrophs in freshwater biomes.

Keywords: diazotrophs, $\mathrm{N}$-fixation, lake, hypolimnion, nifH gene 


\section{INTRODUCTION}

Recent studies in deep marine waters have revealed active $\mathrm{N}$-fixation and a wide diversity of non-cyanobacterial N-fixers (Farnelid et al., 2013; Bombar et al., 2016; Gradoville et al., 2017). The metabolic process by which atmospheric dinitrogen gas $\left(\mathrm{N}_{2}\right)$ is transformed to biologically more reactive forms is known as diazotrophy (Howarth et al., 1988). Despite the ecological and biogeochemical significance of this process, there is limited knowledge about the distribution of this trait in different freshwater microorganisms. In particular, very little is known about non-cyanobacterial diazotrophs in freshwater systems, while at the same time, many of these ecosystems feature steep redox gradients and anoxic zones that might provide unique habitats for previously unrecognized N-fixers.

Only select Archaea and Bacteria have the ability to transform and assimilate $\mathrm{N}_{2}$ gas, and the key enzyme to mediate this process is the nitrogenase (Canfield et al., 2010). Three nitrogenases co-exist in nature: molybdenumiron (Mo-nitrogenase), vanadium-iron, and iron-only (Fe-only nitrogenase). The corresponding gene clusters involved are nifHDK (molybdenum-iron), vnfHGDK (vanadium-iron), and anfHGDK (Fe-only). Mo-nitrogenase is found in all diazotrophs, and its expression is regulated by Mo concentration. Vanadiumiron nitrogenase is present in some microorganisms and may be expressed when Mo is scarce. The other alternative nitrogenase, Fe-only, has dual enzymatic functions and may simultaneously reduce $\mathrm{N}_{2}$ and $\mathrm{CO}_{2}$ to $\mathrm{CH}_{4}$ and $\mathrm{H}_{2}$ in a single enzymatic step (Zheng et al., 2018).

As a result of metatranscriptomic oceanic surveys, significant expression of genes associated with $\mathrm{N}$-fixation has been found in water below the photic zone. This implies a hitherto unrecognized non-cyanobacterial contribution to global marine $\mathrm{N}$-fixation. The $\mathrm{N}$-fixation activity of these non-cyanobacterial diazotrophs is typically associated with energy sources other than oxygenic photosynthesis (Farnelid et al., 2013). With the introduction of new high-throughput sequencing technologies and well-described marker genes such as nifH and nifD, the list of identified marine microorganisms potentially capable of $\mathrm{N}$-fixation has grown in recent years. For instance, many proteobacterial diazotrophs (typically described as "heterotrophic N-fixers") have been found to be abundant, widespread, and sometimes numerically dominant diazotrophs in the ocean (Bombar et al., 2016; Gradoville et al., 2017). In a $\mathrm{N}$-fixation study carried out across the chemocline of the central Baltic Sea, two gammaproteobacterial-like nifH containing gene clusters, EQF91 and ALHOU, were targeted by quantitative PCR (qPCR) and could be associated to active $\mathrm{N}$-fixation despite ample availability of bio-assimilable $\mathrm{N}$ compounds (Farnelid et al., 2013). A more recent study conducted in the California Current System (Gradoville et al., 2017) identified representatives within the diazotrophic community from anaerobic members of Deltaproteobacteria and Betaproteobacteria, highlighting the variability in the composition and metabolic functioning of marine diazotrophs. Interestingly, non-cyanobacterial marine diazotrophs seem to fix $\mathrm{N}_{2}$ in waters where inorganic $\mathrm{N}$ concentrations were still sufficient to support growth
(Bombar et al., 2016). This contradicts observations in earlier studies, in which Cyanobacteria appeared responsible for most planktonic N-fixation (Howarth et al., 1988) and may point to less constrained regulation of diazotrophy among the heterotrophic N-fixers.

Many questions remain regarding the broader role of $\mathrm{N}$-fixers in freshwater ecosystems, the identity of important diazotrophs, and the metabolic traits enabling them to carry out the energydemanding N-fixation. A pioneering study in Lake George, New York (Zani et al., 2000) attributed the active freshwater nifH phylotypes mainly to unicellular and filamentous Cyanobacteria, Alphaproteobacteria, and Gammaproteobacteria. A study carried out by Halm et al. (2009) in the Lake Cadagno (Switzerland), reported for the first time that green sulfur bacteria (GSB), namely, Chlorobi, could be involved in freshwater N-fixation. In this study, they also targeted nifH genes expressed as mRNA, showing that $\mathrm{N}$-fixers were more active at the chemocline. By in situ hybridization-secondary ion mass spectroscopy, they further verified active diazotrophy in Chlorobi. Focusing on deep lake sediments rather than the overlying waters, Parro et al. (2017) also recorded the presence of nitrogen fixation gene products using immunodetection and hypothesized that these were associated with non-cyanobacterial diazotrophs such as Azospira and Arcobacter seen in 16S rRNA inventories. Further, a phylogenetically diverse group of non-cyanobacterial diazotrophs was recently suggested to dominate $\mathrm{N}$-fixation in permafrost thaw ponds, and were possibly engaged in syntrophic relationship with methanogenic Archaea residing in these ponds (Fernandez et al., 2019). However, many freshwater diazotrophs, particularly those inhabiting the darker waters of lakes, have remained unexplored.

Here, we studied the temporal dynamics of potential diazotrophs by analyzing metagenomic sequence data and environmental parameters from epilimnetic and hypolimnetic waters of Trout Bog Lake (Wisconsin, United States), representing a lake type typical for boreal regions. This direct sequencing approach avoids the pitfalls and limitations introduced by primer coverage and other inevitable biases related to PCR-based assays. The samples were collected from early spring to autumn across three consecutive years, providing the first broader account of the temporal dynamics of diazotrophs in humic lakes. We also describe the main genomic features of the most abundant diazotrophs in the anoxic bottom waters (hypolimnion) of Trout Bog Lake by analyzing metagenome assembled genomes (MAGs). The thermal stratification in the small and sheltered Trout Bog Lake is very stable during the warm period of the year. Furthermore, the water has high allochthonous dissolved organic carbon concentration, and thus, light penetration is limited to a shallow upper layer (Baines et al., 2000). The deep waters in stably stratified freshwater lakes are frequently anoxic for extended periods of time (depending on the oxygen demand associated with microbial respiration) until brief mixing events may inject oxygen during the spring and autumn. Such anoxia may favor N-fixing activity, as oxygen is known to be a potent inactivator of nitrogenases. Despite the fact that high $\mathrm{N}$-fixation capacity is often associated with eutrophication, Linz et al. (2018) calculated significantly higher 
levels of nitrogenase marker genes in the hypolimnion of Trout Bog Lake compared to the eutrophic and highly productive Lake Mendota (also located in Wisconsin, United States). This finding corroborates that seasonally anoxic hypolimnetic waters of humic lakes (such as Trout Bog Lake) may well be an overlooked habitat for N-fixers. Thus, based on genomic data, we aimed to also analyze alternative energy production pathways which may potentially fuel $\mathrm{N}$-fixation in such light limited environments.

\section{MATERIALS AND METHODS}

\section{Trout Bog Lake Dataset}

We included metagenome data from 42 epilimnetic and 45 hypolimnetic samples corresponding to the project Trout Bog Hypolimnion and Epilimnion Combined Assembly (Project JGIID: 416375), downloaded from the Department of Energy Joint Genome Institute (JGI) Genome Portal (Grigoriev et al., 2011). The data consisted of paired-end Illumina reads (average length approximately $200 \mathrm{bp}$ after merging forward and reverse reads) (Bendall et al., 2016). The samples were collected from spring to autumn (or late summer depending on the year). The time series spanned a period from 2007 to 2009 . Temperature and dissolved oxygen were measured throughout the sampling campaigns. In summary, the water temperature in the hypolimnion was approximately $5^{\circ} \mathrm{C}$ during the collection period, and suboxic conditions prevailed (dissolved oxygen concentration below $0.5 \mathrm{mg} \mathrm{l}^{-1}$ in most of the samples). More detailed information on the environmental data from Trout Bog's epilimnion and hypolimnion can be found in previous work by Linz et al. (2017) and Table 1.

\section{Enumeration of nifH Using Genomes in JGI-IMG}

To measure nifH abundances, we used merged but unassembled reads. We compared all reads to genomes in JGI-IMG, including previously published MAGs from Trout Bog Lake (Bendall et al., 2016). These MAGs were assembled by Bendall et al. (2016) using metagenomes from a seasonal sampling over three consecutive years at Trout Bog Lake. Their assembly method was a "combined assembly" with samples pooled by layer (epilimnion or hypolimnion) before assembly (Bendall et al., 2016; Linz et al., 2018). Binning contigs into MAGs was based on differential coverage and kmer frequencies using MetaBAT (Kang et al., 2015). All these genomes were previously annotated using IMG tools (Chen et al., 2017) and we are using the naming of the MAGs as in the JGI database (Composite genome 1 to Composite genome 4645).

Our estimates of nifH gene frequencies in the communities were based on searches against reference genomes, MAGs (Bendall et al., 2016) and single amplified genomes (SAGs) from JGI. First, we used MAGs derived from Trout Bog Lake as the subject database. We then amended this with other reference genomes included in the JGI-IMG database (version March 2017) to identify nifH genes that were not represented in the previously assembled Trout Bog MAGs. These had been assembled by Bendall et al. (2016) using the same metagenomic library from
TABLE 1 | Environmental data from 2008.

\begin{tabular}{lccccc}
\hline Date & TN (ppb) & TP $^{\mathbf{( p p b}} \mathbf{~}^{\mathbf{b}}$ & TDN $\mathbf{( p p b )}^{\mathbf{c}}$ & TDP $^{(\mathbf{p p b})} \mathbf{d}^{\mathbf{d}}$ & Sample \\
\hline 29MAY08 & 575 & 19 & 479 & 12 & Epilimnion \\
13JUN08 & 551 & 23 & 447 & 11 & Epilimnion \\
24JUN08 & 629 & 31 & 417 & 15 & Epilimnion \\
08JUL08 & 678 & 134 & 548 & 109 & Epilimnion \\
22JUL08 & 1187 & 61 & 1019 & 38 & Epilimnion \\
05AUG08 & 758 & 38 & 509 & 17 & Epilimnion \\
19AUG08 & 865 & 46 & 585 & 22 & Epilimnion \\
19SEP08 & 679 & 40 & - & - & Epilimnion \\
29MAY08 & 1049 & 43 & 456 & 15 & Hypolimnion \\
13JUN08 & 1152 & 49 & 987 & 35 & Hypolimnion \\
24JUN08 & 1140 & 53 & 853 & 35 & Hypolimnion \\
08JUL08 & 1161 & 63 & 999 & 42 & Hypolimnion \\
22JUL08 & 684 & 36 & 527 & 15 & Hypolimnion \\
05AUG08 & 1152 & 57 & 895 & 34 & Hypolimnion \\
19AUG08 & 1117 & 65 & 1024.5 & 45 & Hypolimnion \\
19SEP08 & 1513 & 60 & & & Hypolimnion \\
\hline
\end{tabular}

a Total nitrogen (TN) in parts per billion. ${ }^{b}$ Total phosphorus (TP) in parts per billion. ${ }^{c}$ Total dissolved nitrogen (TDN) in parts per billion. ${ }^{d}$ Total dissolved phosphorus (TDP) in parts per billion.

Trout Bog Lake that was used for nifH screening in the current work. Nitrogenase gene annotations were compared to Pfam (Finn et al., 2014), KEGG Orthology (KO) (Kanehisa et al., 2016), and COG-based annotations downloaded for JGI-IMG. If any of these annotations pointed to a different function, all reads recruiting to that gene were excluded from further analysis. The relative nifH frequency was estimated as the total number of nif $H$ hits compared to the total number of sequences used as input (metagenomic library size). This procedure was applied to calculate the proportions of nitrogenase genes in both epilimnetic and hypolimnetic samples. If the identified nifH sequence did not match any of the Trout Bog MAGs (Bendall et al., 2016), our implementation of the nifH enumeration method repeated the recruitment using the entire JGI-IMG collection of isolate genomes, MAGs, and SAGs as references. To retrieve taxonomic information about the reads, only high-confidence predictions were considered, using e-value $=10^{-20}$ as a cut-off and a percentage of identity $=95 \%$. When several BLAST hits were exceeding these cut-off values, the taxonomic assignment of the hit with the highest percentage of identity and the lowest e-value was used. Thus, only one taxonomic classification was assigned per metagenomic read to avoid multiple counts. MAGs assembled using metagenomic data from Trout Bog Lake, as well as isolate genomes and SAGs from the entire IMG collection, where at least one copy of a putative nifH gene was found, are listed in Supplementary Table S1. Less than 1\% of the reads assigned to a nitrogenase gene could not be classified in the taxonomic analysis.

\section{The Collection of Nitrogenase Positive Metagenome Assembled Genomes}

To identify MAGs carrying nitrogenase genes (hereafter called nitrogenase positive MAGs), we used nitrogenase gene 
annotations as described above for nifH gene frequency analysis. In brief, gene sequences within the bin had to be classified as a nifH gene by all three annotation systems (KO, PFAM, and COG) (\% identity $>95 \%$ ) for the MAG to be considered a nitrogenase positive genome.

For further analysis, we selected representative genome bins where nifH abundances exceeded 50 nifH reads per phylotype, summed across the Trout Bog Lake hypolimnion time series from 2007 to 2009 (Supplementary Table S2). Our estimate of the abundances of nifH genes in the communities was based on BLASTp searches (cut off: 95\% of identity) against MAGs (Bendall et al., 2016) derived from Trout Bog Lake as the subject database. The relative nifH frequency was estimated as the total number of nifH assigned hits compared to the total number of sequences used as input. Two MAGs with high nifH abundances in the time series from 2007 to 2009 were assembled from epilimnion data [i.e., Composite genome 211 (scaffold: TE211DRAFT TBepi metabat 211 1000175.54) and Composite genome 2493 (scaffold: TE2493DRAFT TBepi metabat 2493 1001483.68)]. However, the rest of the MAGs analyzed here (15 MAGs) were assembled using DNA data collected from Trout Bog hypolimnion samples (see Supplementary Table S2 and the scaffolds used for nitrogenase gene clusters reconstruction listed below). In addition, we checked for genome completeness to select high quality MAGs for whole genome analysis to determine functional capabilities of the contributing organisms (Table 2 and Supplementary Table S2). KEGG annotation system was used for the whole genome analysis (Supplementary Files in https:/github.com/ microbioinformatic/Trout-Bog-diazotrophs).

In addition to the phylogenetic description provided by JGIIMG and the information included in a previous publication (Linz et al., 2018), PhyloPhlAn (Segata et al., 2013) was used to improve phylogenetic and taxonomic classification for some

TABLE 2 | JGI-IMG information about the MAGs used in the whole genome analysis.

\begin{tabular}{|c|c|c|c|}
\hline Genome & $\begin{array}{l}\text { Affiliation } \\
\text { (IMG) }^{*}\end{array}$ & $\begin{array}{c}\text { Genome } \\
\text { completeness (\%) }\end{array}$ & $\begin{array}{l}\text { IMG* genome } \\
\text { ID }\end{array}$ \\
\hline $\begin{array}{l}\text { Composite } \\
\text { genome } 254\end{array}$ & $\begin{array}{l}\text { Bacteria; } \\
\text { Acidobacteria }\end{array}$ & 80 & 2582580662 \\
\hline $\begin{array}{l}\text { Composite } \\
\text { genome } 4645\end{array}$ & $\begin{array}{l}\text { Bacteria; } \\
\text { Proteobacteria }\end{array}$ & 88 & 2582580689 \\
\hline $\begin{array}{l}\text { Composite } \\
\text { genome } 433\end{array}$ & $\begin{array}{l}\text { Bacteria; } \\
\text { Proteobacteria }\end{array}$ & 77 & 2582580684 \\
\hline $\begin{array}{l}\text { Composite } \\
\text { genome 2922.v2 }\end{array}$ & $\begin{array}{l}\text { Bacteria; } \\
\text { Proteobacteria }\end{array}$ & 93 & 2593339183 \\
\hline $\begin{array}{l}\text { Composite } \\
\text { genome } 111\end{array}$ & Bacteria; Chlorobi & 92 & 2582580651 \\
\hline $\begin{array}{l}\text { Composite } \\
\text { genome } 211\end{array}$ & Bacteria; Chlorobi & 94 & 2582580622 \\
\hline $\begin{array}{l}\text { Composite } \\
\text { genome 3520v2 }\end{array}$ & Bacteria; Chlorobi & 89 & 2593339184 \\
\hline $\begin{array}{l}\text { Composite } \\
\text { genome } 2493\end{array}$ & Bacteria; Chlorobi & 89 & 2582580625 \\
\hline
\end{tabular}

*JGl's Integrated Microbial Genomes (IMG) database. poorly characterized putative diazotrophic MAGs downloaded from JGI-IMG (Supplementary Table S2). Interactive tree of life (iTOL) was used for phylogenetic tree visualization (Letunic and Bork, 2016). To build the tree, we also included other relevant genomes downloaded from JGI-IMG as references.

\section{Nitrogenase Gene Clusters Reconstruction}

Genomic features analysis and neighborhood analysis of the nifH genes for the MAGs were done and visualized using Easyfig (Sullivan et al., 2011). To create GenBank annotation files for the CoDing Sequences (CDSs) needed for input to Easyfig, we used EMBOSS 6.6.0 release (seqret). With this tool, we converted the generic feature format (GFF) files downloaded from the JGI Genome Portal to GenBank format.

The scaffolds included in the GFF files and used to analyze different nifH operon structures were:

Chlorobi: (I) Composite genome 111 (scaffold: TH111DRAFT TBhypo metabat 111 10000140.1), (II) Composite genome 211 (scaffold: TE211DRAFT TBepi metabat 211 1000175.54), (III) Composite genome 2493 (scaffold: TE2493DRAFT TBepi metabat 2493 1001483.68), (IV) Composite genome 3520v2 (scaffold: TH03520DRAFT TH03520 TBL comb47 HYPODRAFT 10004746.48).

Acidobacteria: Composite genome 254 (scaffold: TH254DRAFT TBhypo metabat 254 10001420.155). Sulfurimonas: Composite genome 1998 (scaffold: TH1998DRAFT TBhypo metabat 1998 10000844.40). Verrucomicrobia: (I) Composite genome 2747 (scaffold: TH2747DRAFT TBhypo metabat 2747 10008023.254) and (II) Composite genome 2270v2 (scaffold: TH02270DRAFT TH02270 TBL comb47 HYPODRAFT 10000592.10).

Methylococcales: (I) Composite genome 3552 [scaffolds: (A) TH3552DRAFT TBhypo metabat 3552 10001230.12, (B) TH3552DRAFT TBhypo metabat 3552 10006655.34] and Composite genome 2062v2 [scaffolds: (A) TH02062DRAFT TH02062 TBL comb47 HYPODRAFT 10005551.84, (B) TH02062DRAFT TH02062 TBL comb47 HYPODRAFT 10000828.15].

Deltaproteobacteria: (I) Composite genome 4645 (scaffold: TH4645DRAFT TBhypo metabat 4645 10001890.329), (II) Composite genome 2922v2 (scaffold: TH02922DRAFT TH02922 TBL comb47 HYPODRAFT 10000417.24), (III) Composite genome 433 (scaffold: TH433DRAFT TBhypo metabat 433 10016042.145).

Betaproteobacteria: (I) Composite genome 2160 (scaffold: TH2160DRAFT TBhypo metabat 2160 10003883.171), (II) Composite genome 2159 (scaffold: TH2159DRAFT TBhypo metabat 2159 10000110.67).

\section{Statistical Analyses}

All the statistical analyses were performed in $\mathrm{R}$ version 3.3.2 (2016-10-31) (R Core Team, 2016). For data visualization, we used the package ggplot2 (Wickham, 2009). The R scripts used to generate the main figures and statistical analysis are available at https://github.com/microbioinformatic/Trout-Bog. 


\section{RESULTS AND DISCUSSION}

As information about freshwater diazotrophs is scarce, particularly in non-photic zones, we analyzed nifH seasonal variation and classified nifH positive MAGs to Trout Bog Lake time series samples. With these analyses, we identified the potential $\mathrm{N}$-fixing taxa common in the hypolimnion. Additionally, we examined the nif operon of the main taxonomic groups to catalog genes with a primary role in $\mathrm{N}$-fixation.

\section{Identity of Diazotrophs}

We identified eight main phylogenetic groups from Trout Bog hypolimnetic water samples accounting for most of the observed nifH gene phylotypes (see section "Materials and Methods"). The main phylotypes corresponded to (1) Sulfurimonas within the Epsilonproteobacteria, (2) Geobacter and (3) Desulfobacterales within Deltaproteobacteria, (4) Methylococcales within Gammaproteobacteria, as well as (5) Acidobacteria, (6) Betaproteobacteria, (7) Verrucomicrobia, and (8) Chlorobi (Supplementary Figure S1).

\section{Seasonal Shifts in nifH Gene Abundances and the Relationship to Environmental Factors}

The relationship between nifH abundances and environmental conditions were analyzed for year 2008, as this was the only year for which the environmental data exist. Potential diazotrophs in the epilimnion and hypolimnion showed similar maximum abundances ( $\sim 0.030 \%$ nitrogenase genes per sample) during 2008 (Figure 1). The nitrogenase gene abundances were not related to dissolved oxygen and peaks in nitrogenase gene frequencies occurred independently of oxic/anoxic conditions (Figure 1A). However, the relative abundance of potential $\mathrm{N}$-fixers in individual epilimnetic samples usually reached values exceeding $0.025 \%$ (nitrogenase relative total reads) on occasions when average DO was lower than the epilimnetic average (heat map in Figure 1A). The position of the chemocline occasionally compromised the collected epilimnetic samples, causing an apparent reduction in average DO levels. For instance, the upper 2-3 m layer of the anoxic bottom water was included in the supposedly epilimnetic DNA sample on 15 July 2008, 25 August 2008, and 9 September 2008. The seasonal shifts observed within the potential $\mathrm{N}$-fixers in epilimnion and hypolimnion abundances were not significantly linearly correlated to any other environmental parameters measured, including TN, TDN, TP, and TDP (Figure 1 and Table 1). Interestingly, TN:TP ratio and nitrogenase gene abundances followed a polynomial function, with a turning point at a TN:TP of around 20 for both the epilimnion and hypolimnion. This may suggest a response of $\mathrm{N}$-fixers to the TN:TP ratio in this humic lake (Figure 1B), independent of sampling depth and oxygen availability.

The seasonal profile of nitrogenase gene abundances differed between the epilimnion and hypolimnion, suggesting contrasting environmental controls acting on $\mathrm{N}$-fixers in the respective water masses (Figure 1A). For the hypolimnion specifically, diazotrophs were less abundant during May (early-middle spring) (Figure 1A). This suggests that hypolimnetic diazotrophs were poor competitors during this time of the year, which is generally characterized by spring mixing, a large influx of terrestrial matter from snowmelt, and gradual onset of thermal stratification. Associated with these overall dynamics in nifH relative abundance, we observed major changes in the taxonomic association of nifH genes as identified by IMG tools (Figure 2). After the spring mixing, Proteobacteria affiliates became abundant members of the nifH encoding subcommunity. In contrast, Chlorobi growth seemed to be favored by stable stratification and truly anoxic conditions, prevailing from June to October in Trout Bog Lake.

Even if neither TN nor TDN alone were correlated to the seasonal shifts observed in the nitrogenase gene abundances, the prevalence of potential diazotrophs was favored by low TN:TP $(<20)$. Interestingly, the growth of marine microorganisms in general reach an inflection point at $\mathrm{N}: \mathrm{P}(=22)$ (average particulate ratio) (Martiny et al., 2014). Furthermore, active $\mathrm{N}$-fixation seems to prevail in $\mathrm{N}$-rich marine waters if $\mathrm{P}$ is also present and the ambient N:P is low (Bombar et al., 2016). So, how can aquatic diazotrophs stay competitive at high TN or TDN concentrations? Why would $\mathrm{N}$-fixers maintain $\mathrm{N}$-fixation ability while there is plenty of ammonia or nitrate available? These two questions remain unresolved, but there is growing evidence that $\mathrm{N}$-fixation can stabilize and maintain an ideal intracellular redox state, a finding that decouples $\mathrm{N}$-fixation from the function of exclusively satisfying the cellular $\mathrm{N}$ demand (Bombar et al., 2016).

\section{Freshwater and Marine Non-cyanobacterial Diazotrophs}

The retrieved information about the seasonal nifH gene variance as an indicator of diazotroph abundances in Trout Bog Lake enabled us to perform a comparison between marine and freshwater microorganisms carrying the nifH gene beyond the well-studied diazotrophic Cyanobacteria.

Diverse sets of non-cyanobacterial nitrogenase gene phylotypes have indeed been described previously in both surface and deep marine waters (Farnelid et al., 2013; Bombar et al., 2016; Gradoville et al., 2017). In an extensive survey in the Pacific Ocean, the nitrogenase gene pool mainly consisted of cyanobacterial nifH phylotypes in the North Pacific, while Alpha- and Betaproteobacteria were very abundant across the depth gradient in the South and Northwest Pacific. Below the chemocline in the central Baltic Sea, nitrogenase gene and transcript libraries further showed that the N-fixer community consisted mainly of Alpha-, Beta-, and Gammaproteobacteria and diverse anaerobes including Desulfovibrio spp. and archaeal methanogens (Hsu and Buckley, 2009; Farnelid et al., 2013; Gradoville et al., 2017). This is different from what we observed in the hypolimnetic water mass of Trout Bog Lake, where Chlorobi dominated the potential diazotrophic communities. In agreement with our observations, Chlorobi and Proteobacteria were previously shown to be dominant in the sub-chemocline waters of meromictic Lake Cadagno during August, and in this setting, Chlorobi were also shown to be an active N-fixer based on isotope probing results (Halm et al., 2009). Further, Chlorobi was 


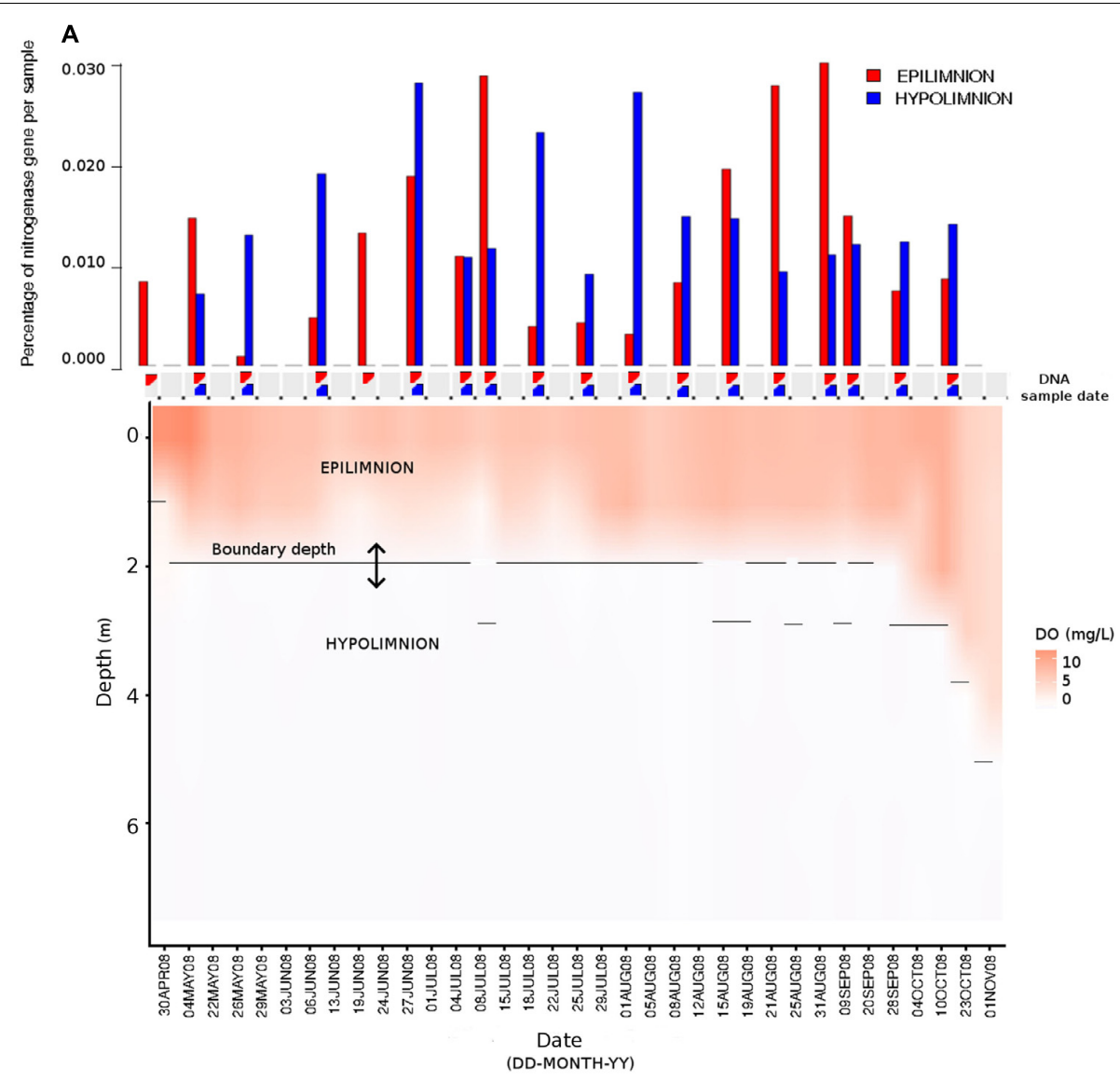

B
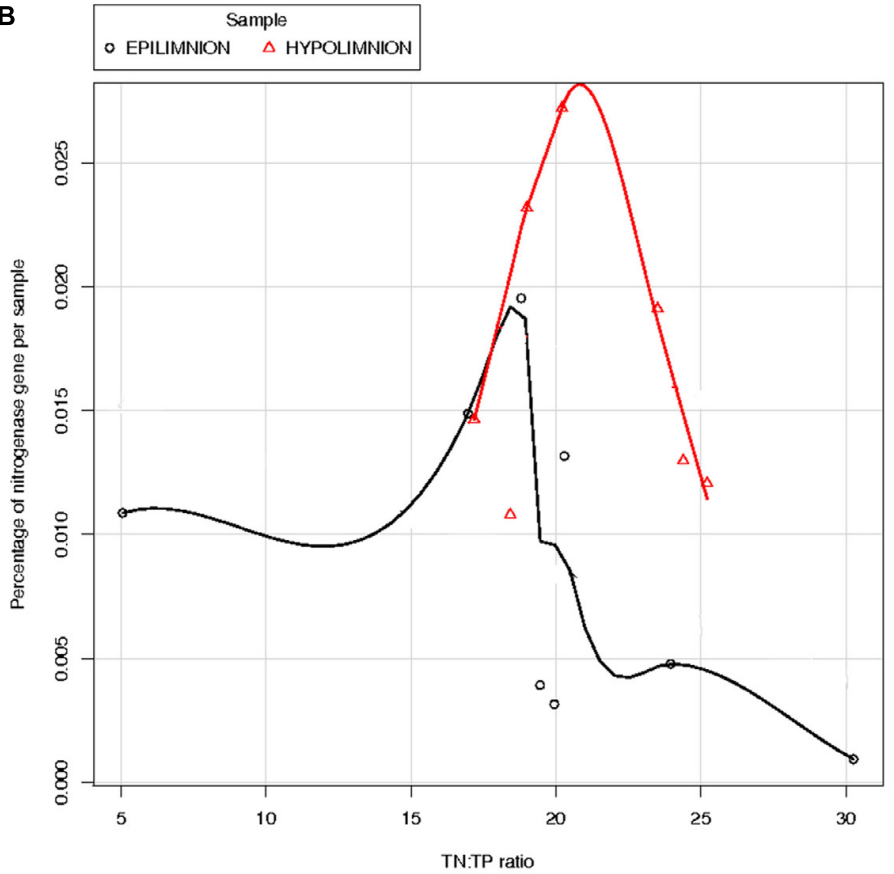

FIGURE 1 | Comparison between nitrogenase gene abundances calculated from epilimnion and hypolimnion and environmental data during 2008 sampling campaign. (A) Nitrogenase gene percentages calculated using IMG annotations (bar plot: in red epilimnion and blue hypolimnion). The approximate depth and date when the DNA samples were collected are depicted with triangles (red = epilimnion and blue = hypolimnion). Dissolved oxygen (mg/L) is showed as a continuous heat map. (B) The relationship between TN:TP ratio (measured in part per billion) and the abundance of nitrogenase genes calculated from epilimnion and hypolimnion using IMG annotations. The polynomial function of non-linear regression is shown in red for hypolimnion and in black for epilimnion. 

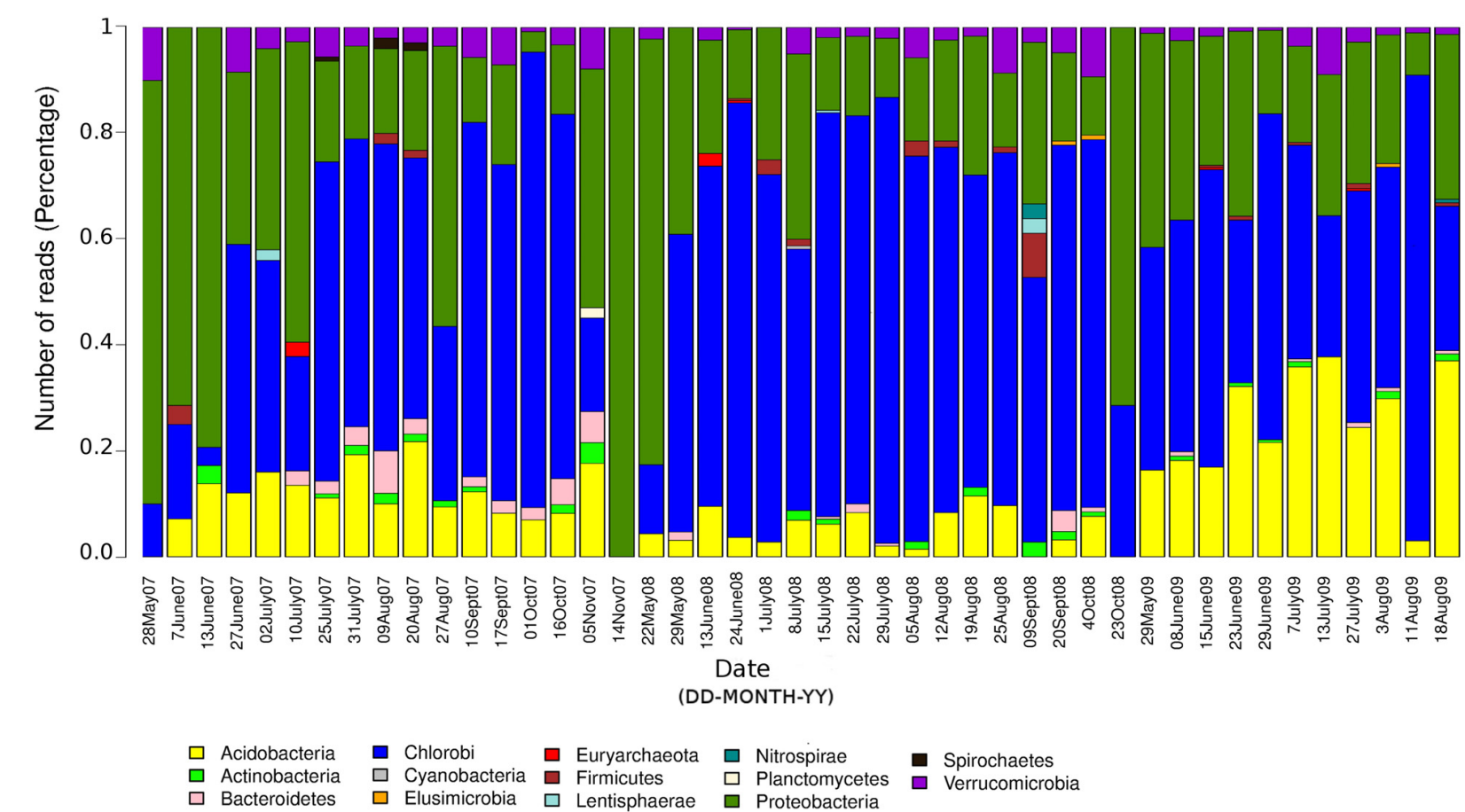

FIGURE 2 | Relative contributions of different taxonomic groups to the potential diazotrophic community in Trout Bog Lake. The nitrogenase phylotype abundances were calculated using nifH reads identified from IMG annotations of assembled sequences and genomes using DNA data collected from hypolimnion.

recently shown to be a major component of the NCD community also in permafrost thaw ponds, accompanied by members of phylum Proteobacteria (Fernandez et al., 2019).

In summary, we conclude that diazotrophs were less abundant during the spring period, possibly because of the large influx of terrestrial organics and nutrients from the snowmelt, which may have favored heterotrophs lacking nif operons. In addition, the prevalence of nif genes seemed to be coupled to photosynthetic bacteria, since nifH phylotype associated with Chlorobi were abundant in many samples (Figure 2). To the best of our knowledge, there are only a few studies (Halm et al., 2009; Thompson et al., 2017) demonstrating in situ diazotrophic potential in Chlorobi, and our results highlight that it may play a widespread significant role within diazotrophic humic lake communities.

\section{Nitrogenase Operon Structure and Accessory N-Fixation Proteins}

In prokaryotes, genes transcribed as an operon are usually regulated by a single promoter. Hence, genes within an operon typically belong to the same or related metabolic pathways (Sullivan et al., 2011). This genome architecture optimizes coordinated use of transcription factors and other regulatory elements in modulating the activity of the organism (Fernandez et al., 2014). Accordingly, we performed an analysis of the nitrogenase operon and surrounding genes (neighborhood analysis) with the purpose of obtaining more information about enzymes transcriptionally or metabolically related to the $\mathrm{N}$-fixation process. Here, we included nifH gene clusters identified within the eight taxonomic groups of $\mathrm{N}$-fixers mentioned above (only MAGs assembled from the seasonal metagenomic data from Trout Bog Lake were used in the analysis). The main genomic features surrounding the nitrogenase gene cluster were transcription factors involved in the regulation of nitrogen cycle processes, molybdenum transporters, enzymes protecting against oxidative stress, and energy metabolism-related proteins (Figures 3-5 and Supplementary Figure S2).

The best studied and most abundant nitrogenase in nature is the Mo-nitrogenase, encoded by nifH, nifD, and nifK genes, found in all N-fixers (Bothe et al., 2010). We observed the presence of nifHDK operon in 15 MAGs in Trout Bog Lake (see Figures 3-5 and Supplementary Figure S2). For the nitrogenase neighborhood analysis, only complete gene clusters were considered, which also included regulatory or accessory $\mathrm{N}$-fixation proteins. For the iron-molybdenum cofactor (FeMoco) synthesis (Rubio and Ludden, 2008; Burén et al., 2019), additional genes nifX, nifE, nif $N$, nifB, and nifV may also be necessary (Chen et al., 2001). Those additional genes usually accompanied the nifHDK cluster (Figures 3-5 and Supplementary Figure S2), but were not universally present. In Methylococcales related genomes (Figure 3), extra copies of nifE, nif $N$, and nifB were located downstream of accessory N-fixation genes: nifQ, nifZ, nifU, nifS, and nifW. These genes were, however, carried in a different gene cluster than nifHDK (Figure 3B). In addition to Gammaproteobacteria, accessory genes nifQ, nifZ, and nifW also appeared in betaproteobacterial 
A

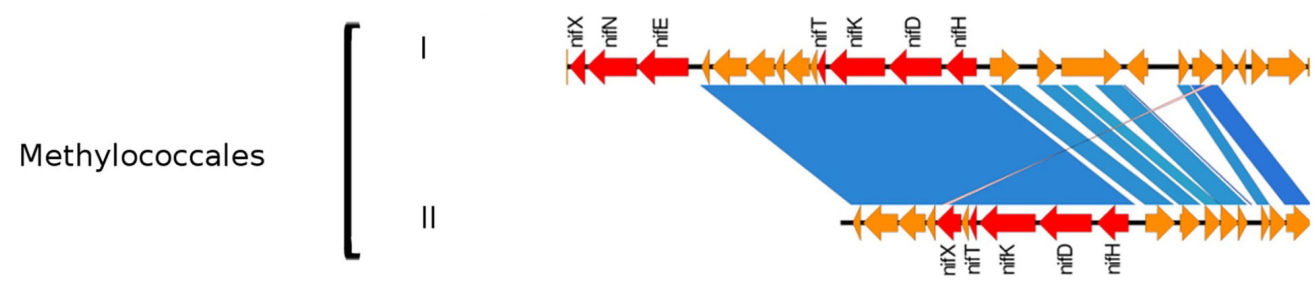

B
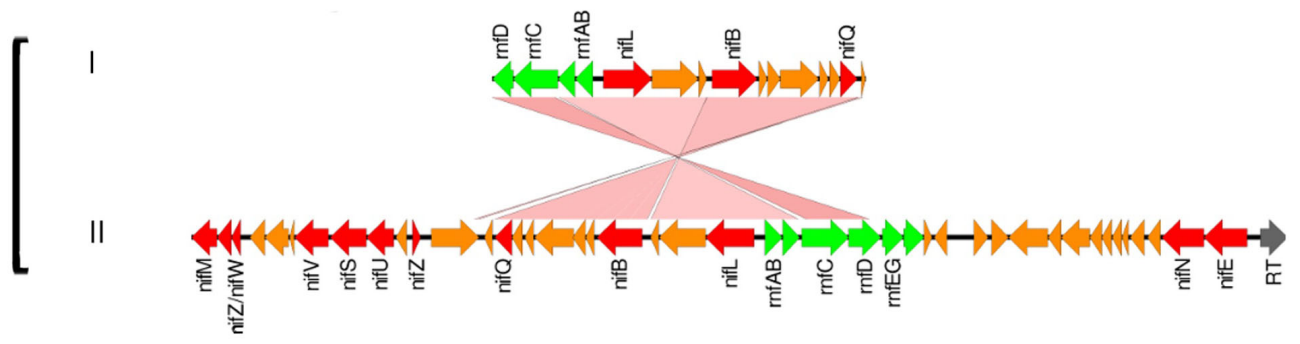

Methylococcales
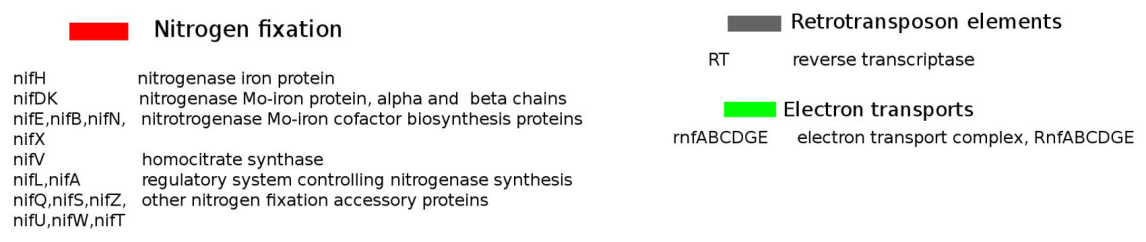

Percentage of identity

$100 \%$
$65 \%$

FIGURE 3 | Alignment of nitrogenase gene clusters of two MAGs corresponding to potential N-fixers classified as Methylococcales (I) Composite genome 3552 [scaffolds: (A) TH3552DRAFT TBhypo metabat 3552 10001230.12, (B) TH3552DRAFT TBhypo metabat 3552 10006655.34] and Composite genome 2062v2 [scaffolds: (A) TH02062DRAFT TH02062 TBL comb47 HYPODRAFT 10005551.84, (B) TH02062DRAFT TH02062 TBL comb47 HYPODRAFT 10000828.15]. (A) The nifHDK gene cluster and (B) accessory N-fixation genes. Coding region sequences (CDS) are colored according to GenBank and KO annotation, with orange representing unknown or unclassified genes. Details of the general functions attributed to the CDS are listed in the color legend.

diazotroph genomes, but in these cases, the genes were located near a cluster formed by nifHDK, nifB, nifE, and nifN (Figure 4). Other N-fixation accessory genes included nifA and nifL (Figures 3, 4), both associated as regulators (Barney et al., 2017) and in some Proteobacteria, their transcription is activated in response of oxygen concentration and fixed nitrogen availability (Martinez-Argudo et al., 2004).

An alternative enzyme for fixing nitrogen, the Fe-only nitrogenase, was present in genomes affiliated with Chlorobi (i.e., Chlorobi III and IV alignment in Figure 5). Feonly nitrogenase as well as Mo-Fe nitrogenase were also found in Rhodopseudomonas palustris, Rhodospirillum rubrum, Rhodobacter capsulatus, and Azotobacter vinelandii, identified by Zheng et al. (2018). The Fe-only nitrogenase from these bacteria can use $\mathrm{CO}_{2}, \mathrm{~N}_{2}$ gas and protons to produce $\mathrm{CH}_{4}$, $\mathrm{NH}_{3}$, and $\mathrm{H}_{2}$ gas in a single enzymatic step (Zheng et al., 2018). The broader relevance and distribution of methanogenesis/Nfixation properties attributed to the Fe-only nitrogenase was first suggested by Zheng et al. (2018). $\mathrm{H}_{2}$ is a common product of the Fe-only nitrogenase with methanogenic activity; interestingly, the Fe-only nitrogenase in the Chlorobi genome (comprised by anfH/nifH, and anfOKGD genes in Figure 5) is placed next to a hydrogenase domain. Based on this and earlier work (Zheng et al., 2018), we suggest that the Fe-only nitrogenase in Chlorobi (III and IV MAGs in Figure 5) may have potentially dual roles in both $\mathrm{N}$-fixation and methanogenesis, also within the system studied here. The possible contribution of $\mathrm{N}$-fixers carrying $\mathrm{Fe}$ only nitrogenase in $\mathrm{CH}_{4}$ production in permafrost thaw ponds was also recently addressed by Fernandez et al. (2019) but no evidence of significant contribution of NCDs to elevated $\mathrm{CH}_{4}$ levels was found.

\section{Genetic Elements Related to Nitrogenase Expression and Activity}

The presence of retrotransposable elements flanking the nifHDK genes in several freshwater populations (Figures 3-5) was a surprising finding, possibly indicating extensive horizontal 


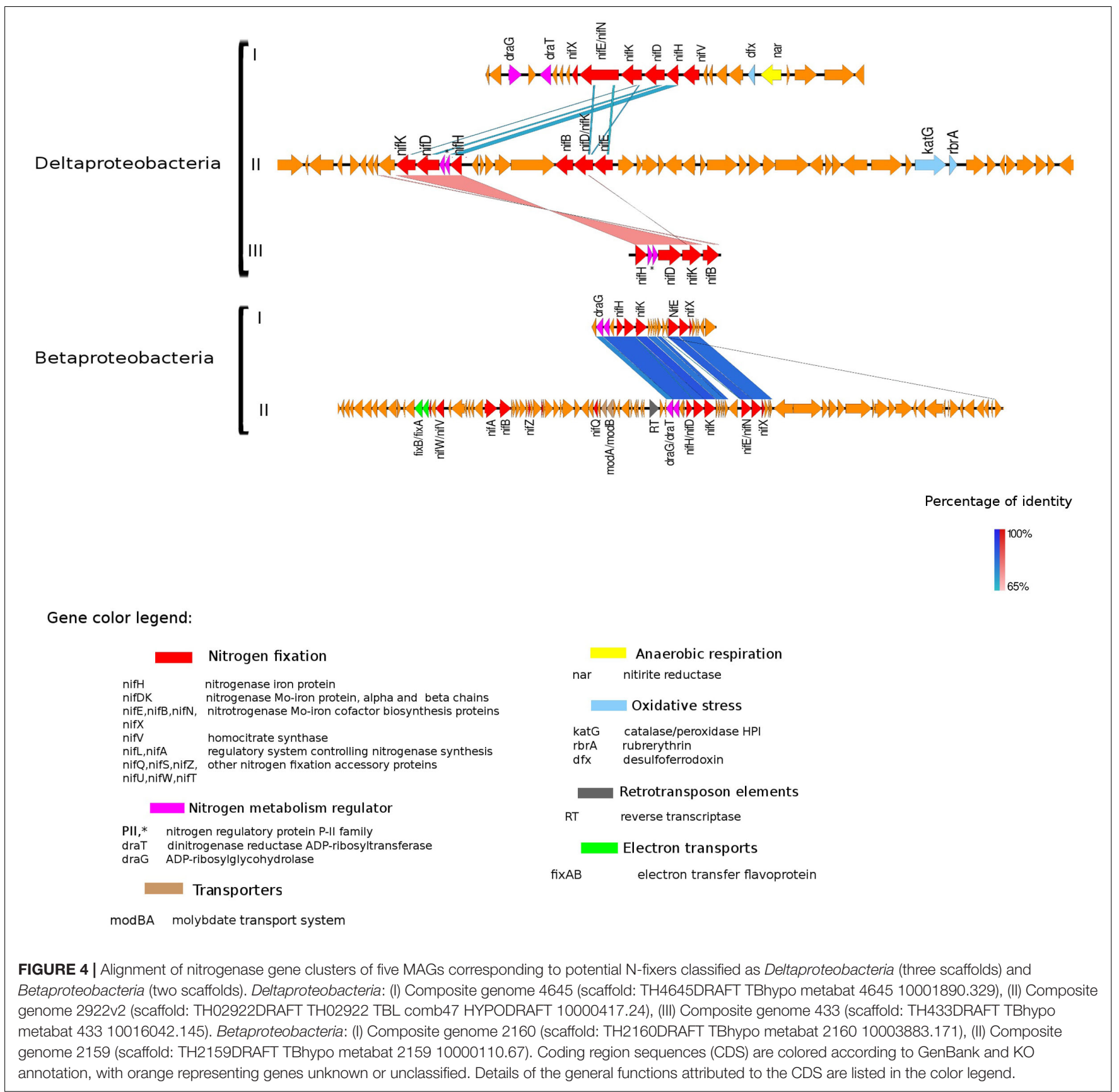

gene transfer. For example, the nitrogenase cluster in Chlorobi (Figure 5) had many features of a retrotransposon. We found coding regions corresponding to reverse transcriptase (RT) and an endopeptidase as well as several direct and inverted repeats (Beauregard et al., 2008) and a predicted AAA-type ATPase (Arias-Palomo and Berger, 2015) (Figure 5). RT was also present in other Trout Bog MAGs (i.e., Betaproteobacteria and Gammaproteobacteria), but it was not possible to identify a complete set of additional and indispensable transposable element genes in these Proteobacteria (Figures 3, 4). Transposases near the nif cluster have been reported before (Xie et al., 2014). However, the dual role of transposons as "gold or trash" (Beauregard et al., 2008) makes the linkages between transposons and the inclusive genes noteworthy. Two non-exclusive hypotheses can explain the term "gold or trash" for a non-parasitic retrotransposon in bacteria. The first hypothesis states that genes carried on the retrotransposon may no longer be beneficial for the host and will eventually be lost during evolution. The second hypothesis emphasizes the role of the transposon in the regulation of gene expression, coupled with the ability to make extra copies of the desired genes if needed (Beauregard et al., 2008). We believe that both of these scenarios could be relevant for $\mathrm{N}$-fixing ability on contemporary Earth. 


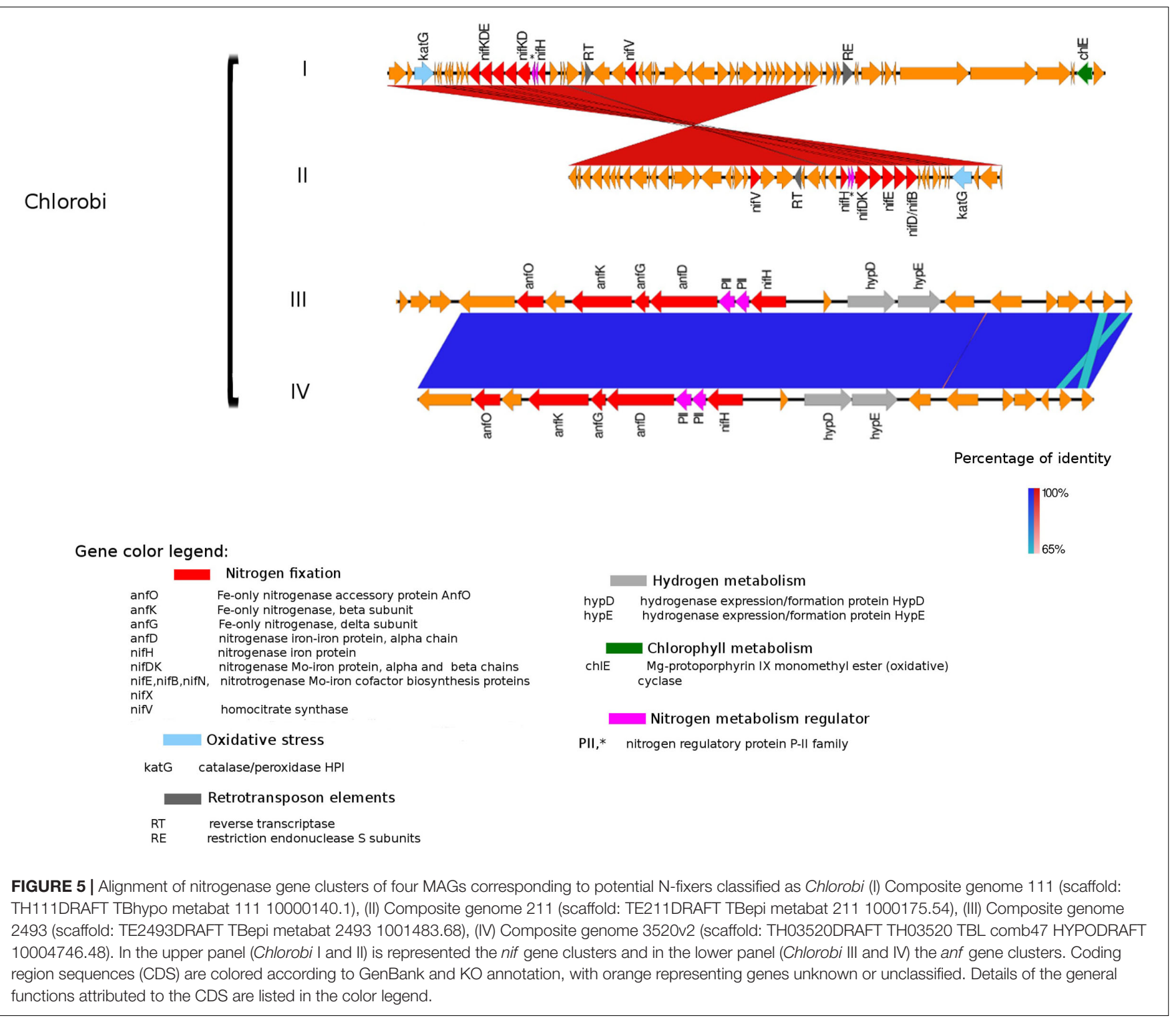

Genes coding for post-translationally modifying proteins, such as the PII family and DraG/DraT, were also found adjacent to nifH or merely hundreds of base pairs away from the nifHDK cluster. The presence of PII regulator genes was characteristic for Chlorobi (Figure 5), and we also observed this feature in Desulfobulbaceae (Deltaproteobacteria II and III in Figure 4). In contrast, $d r a G$ and $d r a T$ genes were present in most representatives of nifH positive Proteobacteria (Figure 4), Verrucomicrobia, and Acidobacteria (see Supplementary Figure S2). The expression of these two important regulators of nitrogenase activity has been linked to ammonia availability (Bombar et al., 2016). According to the predicted function, PII family proteins, DraG (dinitrogenase reductase activating glycohydrolase) and DraT (dinitrogenase reductase ADPribosyltransferase) all can act as sensors for ammonia concentration and nitrogen limitation status (Chen et al., 2001; Oetjen and Reinhold-Hurek, 2009). Specifically, the target enzymes regulated by PII family proteins are directly involved in N metabolism pathways (Conroy et al., 2007) and can act as nitrogenase switch off in response to ammonia concentration (Kessler et al., 2001). While DraG and DraT proteins are modifiers of the nitrogenase enzyme (Nordlund and Ludden, 2006). DraT catalyzes the inactivation of nitrogenase by ribosylation and DraG can revert its functionality by removal of the ADP-ribosylation from the inactive Fe-Mo protein (Oetjen and Reinhold-Hurek, 2009) thus potentially representing a post-translational regulation system for $\mathrm{N}$-fixation.

In the potential diazotroph genomes analyzed in Trout Bog Lake, carbon fixation genes were detected in most of them, and the regulatory $d r a T$ accompanied $d r a G$ gene was in the vicinity of the nif gene cluster in Delta- and Betaproteobacteria (Figure 4) and Acidobacteria and Verrucomicrobia (Supplementary Figure S2). Bombar et al. (2016) observed that either a disruptive mutation in the DraT, or the absence of this regulator in the 
presence of $\mathrm{DraG}$ coupled with an incomplete $\mathrm{CO}_{2}$ fixation pathway, could be associated with the reliance on $\mathrm{N}$-fixation to maintain an ideal redox state in marine bacteria. In Rhodobacter sphaeroides, isolated from deep lakes, it was shown that electron-demanding nitrogenases could balance redox by producing dihydrogen as a byproduct of $\mathrm{N}$-fixation (Kontur et al., 2011). Still, carbon fixation appeared to be the preferred reduction reaction accepting electrons. Thus, based on our genomic analysis, we hypothesize that if excess reducing power accumulates in the cell, hypolimnetic freshwater diazotrophs may expel the excess of reducing power via $\mathrm{N}$-fixation.

In the hypolimnetic diazotroph communities analyzed here, we observed the presence of nifL in Gammaproteobacteria (Figure 3) and nifA in Betaproteobacteria (Figure 4). The nifA and nifL genes were found next to coding regions for electrontransfer and accessory N-fixation proteins in these Trout Bog MAGs. Both NifL and NifA are well known regulatory proteins affecting the nitrogenase gene expression. NifL acts as antiactivator of NifA, while NifA exerts a direct action on the nitrogenase promoter and increase nifH gene expression. In general, nifL and nifA gene expression responds to environmental and cellular signals such as energy, nitrogen, oxygen, and carbon availability (Barney et al., 2017). The action of NifA has also been linked to the transcriptional activation of genes encoding electron transport proteins (i.e., $f i x A B$ and $r n f$ ). NifA could be involved simultaneously in two process: (i) enhancing $\mathrm{N}$-fixation by increasing nitrogenase expression and (ii) generating ATP by increasing electron transports expression and activity. Thus, the increased ATP yield could be used as fuel for nitrogenase enzyme activity (Sperotto et al., 2004; Barney et al., 2017).

Besides being broadly toxic to microorganisms, various reactive oxygen species (ROS) (i.e., hydrogen peroxide, superoxide) can also inhibit nitrogenase activity (Fay, 1992). Three different genes ( $k a t G, r d r A$, and $d f x$ ), coding for enzymes involved in ROS and oxygen transformation, were found in the proximity of nifHDK gene clusters in several lineages analyzed here (Figures 4, 5).

In Verrucomicrobia and Betaproteobacteria, genes modA and $\bmod B$, required for molybdate uptake, were also interspersed with $\mathrm{N}$-fixation genes (Figure $\mathbf{4}$ and Supplementary Figure S2). In Acidobacteria, the scaffold containing the nifHDK cluster also had regions classified as amino acid transporters (PAAT), surrounded by genes involved in carbon metabolism (Supplementary Figure S2).

In summary, within the eight main taxonomic groups identified, nif operonic structure presented different characteristics. This suggests that diverse mechanisms may be involved in regulating nitrogenase transcription in Trout Bog diazotrophs. As $\mathrm{N}$-fixation is energetically costly and diverts reducing power and ATP from other functions, cells have much to gain from precise and robust regulation of the expression and activity of nitrogenases. In agreement with this, the nitrogenase cluster (neighborhood) analyses suggested tight control of the nif operon. Nevertheless, with only genomic data, we cannot assure that the microorganisms carrying the genes for $\mathrm{N}$-fixation actually use this metabolic option under the prevailing conditions.

\section{Reconstruction of the Central Pathways Related to Energy Metabolism Within Potential N-Fixers}

Expanding our analysis to the whole genome is crucial to evaluate how the main diazotrophic groups deal with the high energy demand needed to perform $\mathrm{N}$-fixation. Hypolimnetic waters of Trout Bog and other humic lakes are characterized by very low irradiance and suboxic to anoxic conditions (Watras et al., 2015). By inspecting the genomes of putative N-fixers, we encountered several options to generate or preserve metabolic energy (ATP) for N-fixation. Here, we limited the analysis to the main taxa highlighted in Supplementary Figure S1 to uncover metabolic strategies associated with $\mathrm{N}$-fixation in autotrophic and heterotrophic potential diazotrophs. Taking into account nifH gene frequencies, Chlorobi, Acidobacteria, and Proteobacteria were the most abundant phyla during the sampling period. Therefore, we focused the metabolic analysis on the functional annotation of Trout Bog MAGs affiliated with these three groups, representing in total eight MAGs. The estimated completeness for the MAGs included in this analysis is reported in Table 2.

\section{Chlorobi}

Following the nifH operon and surrounding genes analysis, we started with the reconstruction of bacteriochlorophyll and carotenoid biosynthesis pathways. Both of these pigments are necessary for assembling the chlorosome, which constitutes the central structure for anoxygenic photosynthesis within Chlorobi, Chloroflexi, and Acidobacteria (Pšenčik et al., 2014). The genes involved in chlorosome formation and the central transformations in which their coding proteins participate are illustrated in Supplementary Figure S3. Only one essential gene, bciC (EC 3.1.1.100 enzyme in Supplementary Figure S3), related to bacteriochlorophyll $\mathrm{c}$ and $\mathrm{d}$ synthesis, was missing in the four MAGs affiliated to Chlorobi, in spite of the high percentage of genome completeness reported by JGI-IMG (from 89 to $94 \%$, Table 2). Thus, the existence of an almost complete pathway to assemble the chlorosome supports photosynthetic potential in hypolimnetic Chlorobi by means of anoxygenic photosynthesis (Bryant et al., 2012) a process that would be feasible in the environmental conditions seen in the deeper waters of our stratified freshwater system (Xiong et al., 2000). Hydrogen could be an alternative energy source, implicated by the presence of hydrogenase genes. Such a process may also contribute to the removal of $\mathrm{H}_{2}$ and oxygen from the active site of the nitrogenase (Brewin, 1984). The presence of $d s r A B$ genes suggests that Chlorobi can use sulfide as electron donor. DsrAB protein or dissimilatory sulfite reductase is a reversible system that functions in sulfite reduction and sulfur/sulfide oxidation. In the Chlorobi MAGs, we did not identify other enzymes to complete the dissimilatory sulfate reduction pathway, supporting our interpretation that $d s r A B$ may play a role in sulfide oxidation (Müller et al., 2015). Trout Bog Chlorobiales MAGs also contain coding regions for key enzymes involved in the reductive tricarboxylic acid (rTCA) cycle (Linz et al., 2018) suggesting the use of $\mathrm{CO}_{2}$ as carbon source. Thus, based on the 
genomic analyses presented here, the possible mechanisms for electron flow in Chlorobi are photosynthesis, carbon fixation, and sulfide oxidation.

\section{Acidobacteria}

Despite a previous report of potential for chlorosome synthesis in this phylum (Pšenčik et al., 2014), we found no traces of phototrophic ability in the genome of nifH encoding hypolimnetic Acidobacteria. On the other hand, this genome hosted efficient carbon utilization and glycolate metabolism genes indicated by the presence of the cstA (carbon starvation), coxL and cutL (carbon fixation), and $g l c D$ (utilization of glycolate) in the vicinity of the nitrogenase gene cluster (Supplementary Figure S2). In a proteomic study of a soil that was rich in different Acidobacteria strains, coxL protein and different enzymes degrading small $\mathrm{C} 1$ compounds were found to be abundant. High prevalence of $\mathrm{C} 1$ metabolism in genomes from soil, including Acidobacteria, is believed to serve as support for larger enzyme complements involved in complex carbohydrate degradation (i.e., pectin and xylane) (Diamond et al., 2019). The most prominent carbon-related metabolic pathways we found in the nifH encoding Acidobacteria were the Arnon-Buchanan cycle, C4-dicarboxylic acid cycle, incomplete rTCA cycle, reductive pentose phosphate cycle, and phosphate acetyltransferase-acetate kinase pathway. In terrestrial environments, some strains of Acidobacteria appear to have genes for anaplerotic carbon dioxide fixation, a convenient function considering soils harbor pockets of high $\mathrm{CO}_{2}$ concentration (Eichorst et al., 2018). In summary, nifH encoding Acidobacteria in Trout Bog Lake seem to obtain energy and carbon by carbohydrate degradation; however, a principal energy source could not be identified.

\section{Gammaproteobacteria (Methylococcales)}

In Proteobacteria representatives, genes encoding bioenergetic enzymes, such as electron transport chain (ETC) component and the Rnf complex, were located in the neighborhood of nitrogenase related CDS (Figure 3). The Rnf complex has previously been found in Methylococcales (Chistoserdova, 2015). This complex, also detected in Desulfobacterales among the Trout Bog MAGs, is driving reverse electron flux from NADH, thus fueling energy demanding processes in the cell, such as $\mathrm{N}$-fixation in Clostridium ljungdahlii (Tremblay et al., 2013). Thereby, it may provide electrons to the nitrogenase enzyme by contributing to ferredoxine reduction (Tremblay et al., 2013). Furthermore, there are reports that the Rnf complex is involved in the transcriptional and post-translational regulation and maturation of the nitrogenase enzyme in A. vinelandii (Curatti et al., 2005) and Azoarcus sp. strain BH72 (Sarkar et al., 2012). We observed the presence of $r n f$ complex genes placed among $\mathrm{N}$-fixation related genes and regulators in Methylococcales (Figure 3), and in light of this, we suggest a possible role of $r n f$ genes in the transcriptional and post-translational regulation of nitrogenase. Similar nitrogenase cluster organization and related genes arrangements were previously reported in A. vinelandii (Curatti et al., 2005) and Azoarcus sp. strain BH72 (Sarkar et al., 2012).

Genes indicating methylotrophy ( $p m o A, m d h 1, m x a F)$ were identified in nifH encoding Methylococcales MAGs, indicating that $\mathrm{C} 1$ compounds could be a carbon and energy source. In addition, the use of $\mathrm{C} 1$ compounds as electron donor would be coupled with the Rnf complex to transfer reducing power to the nitrogenase reaction.

\section{Deltaproteobacteria}

Within the Desulfobacterales group, dissimilatory sulfate reduction seems to be the respiratory option considering the presence of $d s r$ genes. This was combined with the $r n f$ complex that can drive reverse electron flux (Tremblay et al., 2013) when coupled with energetically poor reaction such as sulfate reduction. This could provide electrons or reduced power in the form of $\mathrm{NAD}(\mathrm{P}) \mathrm{H}$ to fuel cytoplasmic $[\mathrm{NiFe}]$ and $[\mathrm{FeFe}]$ hydrogenases, formate dehydrogenases, and heterodisulfide reductase-related proteins (Pereira et al., 2011). The other representative of Deltaproteobacteria, Geobacter, did not contain any genes for dissimilatory sulfate reduction. Essential genes involved in the Wood-Ljungdahl (WL) pathway were found in both Desulfobacterales and Geobacter. In the Trout Bog MAG affiliated with Geobacter (Composite genome 4645), genes likely to be involved in extracellular electron transfer coupled with humic substances and $\mathrm{Fe}(\mathrm{III})$ reduction have been detected in a previous work (He et al., 2019). The carbon source (or an alternative energy source) detected in Desulfobacterales and Geobacter may be propionate or butanoate, as genes involved in short-chain fatty acid metabolism were found in these MAGs. Thus, according to our analysis, it seems that the main difference within nifH encoding Deltaproteobacteria is the electron sources: $\mathrm{Fe}(\mathrm{III})$ and humic substances in Geobacter, while Desulfobacterales seems to rely on sulfur compounds and Rnf complex to obtain electrons needed to feed the nitrogenase enzyme.

\section{Ecology of Microbial N-Fixers in Freshwater Hypolimnetic Waters}

Analysis of freshwater nifH positive MAGs in this study enabled us to metabolically characterize previously undescribed potential diazotrophs from which we identified several possible metabolic strategies that may fuel $\mathrm{N}$-fixation in the hypolimnion of Trout Bog Lake. The negligible abundance of Cyanobacteria (Linz et al., 2018) suggests that the characteristic environmental conditions of hypolimnetic waters, such as low irradiance, clearly prevented their growth and also likely $\mathrm{N}$-fixation, which relies on energy from the canonical oxygenic photosynthesis via photosystems I and II (Heinz et al., 2016). While there is so far no data supporting that light may be an energy source for non-cyanobacterial but pelagic marine diazotrophs (Bombar et al., 2016), earlier work in meromictic Lake Cadagno suggests that in low irradiance and oxygen depleted hypolimnetic freshwaters, anoxygenic photosynthesis may provide the energy needed for N-fixation (Halm et al., 2009). Our genomic data support this hypothesis. For example, Chlorobi, the predominant hypolimnetic diazotrophic phylotype in Trout Bog Lake, have iron-sulfur-type photosystems enabling ferredoxin reduction and subsequent nitrogenase reduction to carry out $\mathrm{N}$-fixation (Madigan, 2014). This alternative unique antenna system, the chlorosome, makes it possible for Chlorobi to 
obtain energy from a light-harvesting apparatus under lowirradiance and anoxic/suboxic conditions (Oostergetel et al., 2010). This structure constitutes an adaptation to fuel $\mathrm{N}$-fixation at irradiances that are much lower than required for the cyanobacterial photosystems. Chlorobi was also found to be a major organism contributing to $\mathrm{N}$-fixation in permafrost thaw ponds, further supporting this hypothesis (Fernandez et al., 2019). We also found carbon fixation genes (i.e., rTCA cycle and incomplete Calvin cycle) in Chlorobi, supporting the existence of a potential photosynthetic pathway that can be coupled with sulfide as an electron donor (Bryant et al., 2012). Our observations of genes likely encoding enzymes involved in photosynthesis, $\mathrm{N}$-fixation, and carbon fixation in an anaerobic freshwater bacterium extend the potential for primary production deeper into the water column than previously assumed. Nevertheless, this needs to be confirmed with activity tests using stable nitrogen isotopes and transcriptomic analysis.

In Trout Bog Lake, the overlying epilimnetic waters are in contact with the atmosphere and profoundly influenced by aerobic photosynthesis, whereas the underlying hypolimnetic waters typically feature much less dissolved oxygen and become seasonally anoxic in summer. In this sense, hypolimnetic waters in Trout Bog Lake are representative and can be regarded as a model for the significant number of smaller and colored lakes in temperate and boreal regions. The depletion of oxygen is a determining step, as oxygen is a well-known disruptive factor for $\mathrm{N}$-fixation; it can inhibit the nitrogenase enzyme activity, but it also represses nifH gene transcription (Fay, 1992). Thus, the inevitable exposure to oxygen has forced aerobic diazotrophs to develop strategies to couple processes such as the reduction of nitrogen with photosynthesis, as is the case of Cyanobacteria (Berman-Frank et al., 2003). Even if the hypolimnetic waters of Trout Bog Lake rapidly become anoxic after stratification sets in during spring (Linz et al., 2017), we observed the presence of three genes involved in the protection of bacterial cells from oxidative stress and ROS (Figures 4, 5). This may shield the hypolimnetic $\mathrm{N}$-fixers from occasional exposure to oxygen-rich environments, which happens during seasonal overturn or episodic mixing events. There are plenty of other abiotic factors, such as molybdenum availability, that are known to regulate nitrogenase expression and activity. Although Mo is rarely limited, the most abundant nitrogenase is the Mocontaining protein, as this element is required for the assembling of the enzyme. In Betaproteobacteria and Verrucomicrobia, we accordingly observed the presence of Mo transport genes $(\bmod A B)$ in the neighborhood of the nifHDK cluster. For all other potential diazotrophs identified in our dataset, $\bmod A B$ were also present but located elsewhere on their reconstructed genomes. In a well-studied N-fixer, Clostridium pasteurianum, $\bmod A$ and $\bmod B$ genes were interspersed with $\mathrm{N}$-fixation related genes. This is further support for co-regulation of molybdenum transport and N-fixation (Chen et al., 2001). Notably, modAB gene mutations affect nitrogenase activity negatively in Klebsiella pneumoniae, as they required higher levels of molybdate in the medium to fix nitrogen (Imperial et al., 1985).

The use of alternative terminal acceptors for the ETC is crucial for chemotrophic bacteria to mobilize energy from reduced organic compounds in oxygen-depleted waters efficiently. A complete pathway to carry out sulfate reduction was detected in Desulfobacterales. The use of sulfate as an electron acceptor for microorganisms is associated with reduced energy yield compared to use of oxygen, and other more favorable electron acceptors (Muyzer and Stams, 2008) which can partly be compensated by the availability of high-quality organic substrates. In freshwaters, it has been shown that sulfate reducing bacteria can also grow by fermentation using organic compounds as both reductant and oxidant (Muyzer and Stams, 2008). Freshwater sulfate reducing bacteria can also be syntrophically associated with methanogens and oxidize lactate and ethanol, while the hydrogen produced is efficiently removed by methanogenesis (Muyzer and Stams, 2008). In the Desulfobacterales MAGs analyzed here, a complete set of genes involved in the transformation of pyruvate to acetate was present. The WL pathway, which has been described before in organohalide-respiring Dehalococcoides (Zhuang et al., 2014), appeared to be present in these Desulfobacterales MAGs (complete in Composite genome 433 and incomplete in Composite genome 2922v2). The WL pathway can contribute to carbon fixation or energy conservation, depending on the microorganism's physiological requirements (Zhuang et al., 2014). In the case of the WL pathway acting in reverse, generated reducing power from the oxidation of organic compounds may, at least in theory, fuel $\mathrm{N}$-fixation.

\section{CONCLUSION}

We uncovered an abundant and diverse community of noncyanobacterial microorganisms in hypolimnetic lake waters that seems to have the potential to perform N-fixation. Potential diazotrophs were less abundant during the spring period, possibly because of the large influx of terrestrial organics and nutrients from the snowmelt, which may have favored heterotrophs lacking nif operons. In addition, the prevalence of nif genes seemed to be coupled to photosynthetic bacteria, since nifH phylotype associated with Chlorobi were abundant in many samples (Figure 2). To the best of our knowledge, there are only a few studies (Halm et al., 2009; Thompson et al., 2017) demonstrating in situ diazotrophic potential in Chlorobi, and our results highlight that it may play a widespread and significant role also within diazotrophic humic lake communities. Strategies for carbon fixation varied from WL pathway in Deltaproteobacteria to rTCA and reductive pentose phosphate cycle in Acidobacteria, while carbon fixation genes linked to photosynthesis were detected in Chlorobi. NifH positive MAGs classified as Chlorobi are an example that primary production zone may expand to deep water layers in Trout Bog Lake. In summary, carbon fixation and utilization pathways could be linked to N-fixation in the hypolimnion of Trout Bog Lake, and we propose that this finding extends to other humic and stained freshwater systems. In contrast, we observed marked differences in the energy metabolism capabilities regarding terminal electron acceptors and electron transport proteins within the diazotrophic community. We also infer a potential relationship between nitrogenase expression and the rnf complex (electron carrier proteins) in Methylococcales; supported by the structure of the 
operons featuring $r n f$ and $\mathrm{N}$-fixation related genes. Ongoing metatranscriptomic studies in the same bog system may help clarify these linkages and reveal the realized metabolism of the potential diazotrophs identified in this research. Nevertheless, post-translational regulators as identified in our genomic study point to limitations of transcriptomics when studying highly regulated metabolic processes and call for future coordinated analyses of metaproteomes and $\mathrm{N}$-fixation rates.

\section{DATA AVAILABILITY STATEMENT}

The datasets generated for this study can be found in the Joint Genome Institute Genome Portal under the JGI Identification number 416375.

\section{AUTHOR CONTRIBUTIONS}

SB conceived this study and KM supervised the environmental data collection, seasonal experiments, and DNA sequencing protocols. LF analyzed the data, created the main figures, and also drafted a first version of the manuscript. LF, AE, SP, and SB designed the methodologies to analyze $\mathrm{N}$-fixers and analyzed the results. AL contributed with the laboratory work and sampling. All authors have been involved in writing the manuscript as well as analyzing and discussing the results. All authors have read and approved the final version of the manuscript.

\section{FUNDING}

LF and SB were supported by the Swedish Research Council Formas (Grant 2012-986) and the Swedish Research Council (Grant 2017-04422). KM acknowledges funding from the United States National Science Foundation Microbial Observatories Program (MCB-0702395), the Long-Term Ecological Research Program (NTL-LTER DEB- 1440297), and an INSPIRE award (DEB-1344254), and the Wisconsin Alumni Research Foundation.

\section{REFERENCES}

Arias-Palomo, E., and Berger, J. M. (2015). An atypical AAA+ ATPase assembly controls efficient transposition through DNA remodeling and transposase recruitment. Cell 162, 860-871. doi: 10.1016/j.cell.2015.07.037

Baines, S. B., Webster, K. E., Kratz, T. K., Carpenter, S. R., and Magnuson, J. J. (2000). Synchronous behavior of temperature, calcium, and chlorophyll in lakes of northern Wisconsin. Ecology 81, 815-825. doi: 10.1890/0012-9658(2000) 081[0815:sbotca]2.0.co;2

Barney, B. M., Plunkett, M. H., Natarajan, V., Mus, F., Knutson, C. M., and Peters, J. W. (2017). Transcriptional analysis of an ammonium-excreting strain of Azotobacter vinelandii deregulated for nitrogen fixation. Appl. Environ. Microbiol. 83:e01534-17.

Beauregard, A., Curcio, M. J., and Belfort, M. (2008). The take and give between retrotransposable elements and their hosts. Annu. Rev. Genet. 42, 587-617. doi: 10.1146/annurev.genet.42.110807.091549

Bendall, M. L., Stevens, S. L. R., Chan, L. K., Malfatti, S., Schwientek, P., Tremblay, J., et al. (2016). Genome-wide selective sweeps and gene-specific sweeps in

\section{ACKNOWLEDGMENTS}

We thank the North Temperate Lakes, UW-Trout Lake Station, the UW Center for Limnology, and the Global Lakes Ecological Observatory Network for field and logistical support. We also thank the US Department of Energy and the Joint Genome Institute for supporting this work through the Integrated Microbial Genomes (IMG) system and the Community Sequencing Program (CSP 394) and Sarah Stevens for curating the MAGs.

\section{SUPPLEMENTARY MATERIAL}

The Supplementary Material for this article can be found online at: https://www.frontiersin.org/articles/10.3389/fmicb. 2020.01500/full\#supplementary-material

FIGURE S1 | Phylogenetic tree of the potential diazotrophs inhabiting the hypolimnetic waters of Trout Bog Lake. MAGs from Trout Bog Lake containing a nifH gene sequence are included in the tree. Different colors highlight the most abundant groups of possible diazotrophs. For the genome name, we used a shortened version of the IMG full name (i.e., IMG full name: Composite genome from Trout Bog Hypolimnion pan-assembly Tbhypo.metabat.254; short name: Composite genome 254). The numbers above the branches represent the branch length and the numbers inside the blue circles represent the length in the ramification. FastTree tool was used to build the tree. FastTree computes large minimum evolution tree with profiles instead of a distance matrix and was included in the PhyloPhIAn pipeline.

FIGURE S2 | Alignment of nitrogenase gene clusters of four MAGs corresponding to potential nitrogen fixers classified as Acidobacteria (1 scaffold), Sulfurimonas (1 scaffold), Verrucomicrobia (2 scaffolds) (see Material and Methods for more information about the scaffolds used). Coding region sequences (CDS) are colored according to GenBank and $\mathrm{KO}$ annotation, with orange representing genes unknown or unclassified. Details of the general functions attributed to the CDS are listed in the color legend.

FIGURE S3 | Chlorosome formation and anoxygenic photosynthesis genes. The figure presents the central genes and transformations in which their coding proteins are involved. The colored squares represent the group of microorganisms that contains a homologous gene for the illustrated function. The same color legend as in Supplementary Figure $\mathbf{S 1}$ is used to highlight the different phylogenetic categories.

natural bacterial populations. ISME J. 10, 1559-1601. doi: 10.1038/ismej.2015. 241

Berman-Frank, I., Lundgren, P., and Falkowski, P. (2003). Nitrogen fixation and photosynthetic oxygen evolution in cyanobacteria. Res. Microbiol. 154, 157-164. doi: 10.1016/s0923-2508(03)00029-9

Bombar, D., Paerl, R. W., and Riemann, L. (2016). Marine Non-cyanobacterial diazotrophs: moving beyond molecular detection. Trends Microbiol. 24, 916927. doi: 10.1016/j.tim.2016.07.002

Bothe, H., Schmitz, O., Yates, M. G., and Newton, W. E. (2010). Nitrogen fixation and hydrogen metabolism in cyanobacteria. Microbiol. Mol. Biol. Rev. 74, 529-551. doi: 10.1128/mmbr.00033-10

Brewin, N. J. (1984). "Hydrogenase and energy efficiency in nitrogen fixing symbionts," in Genes Involved in Microbe-Plant Interactions. Plant Gene Research (Basic Knowledge and Application, eds D. P. S. Verma and T. Hohn (Vienna: Springer), 179-203. doi: 10.1007/978-3-7091-8739-5_6

Bryant, D. A., Liu, Z., Li, T., Zhao, F., Costas, A. M. G., Klatt, C. G., et al. (2012). "Comparative and functional genomics of anoxygenic green bacteria from the Taxa Chlorobi, Chloroflexi, And Acidobacteria," in Functional Genomics 
And Evolution Of Photosynthetic Systems, eds R. Burnap and W. Vermaas (Dordrecht: Springer), 47-102. doi: 10.1007/978-94-007-1533-2_3

Burén, S., Pratt, K., Jiang, X., Guo, Y., Jimenez-Vicente, E., Echavarri-Erasun, C., et al. (2019). Biosynthesis of the nitrogenase active-site cofactor precursor NifB-co in Saccharomyces. Proc. Natl. Acad. Sci. U.S.A. 116, 25078-25086. doi: 10.1073/pnas.1904903116

Canfield, D. E., Glazer, A. N., and Falkowski, P. G. (2010). The evolution and future of Earth's nitrogen cycle. Science 330, 192-196.

Chen, I.-M. A., Markowitz, V. M., Chu, K., Palaniappan, K., Szeto, E., Pillay, M., et al. (2017). IMG/M: integrated genome and metagenome comparative data analysis system. Nucleic Acids Res. 45, D507-D516. doi: 10.1093/nar/gkw929

Chen, J. S., Toth, J., and Kasap, M. (2001). Nitrogen-fixation genes and nitrogenase activity in Clostridium acetobutylicum and Clostridium beijerinckii. J. Ind. Microbiol. Biotechnol. 27, 281-286. doi: 10.1038/sj.jim.7000083

Chistoserdova, L. (2015). Methylotrophs in natural habitats: current insights through metagenomics. Appl. Microbiol. Biotechnol. 99, 5763-5779. doi: 10. 1007/s00253-015-6713-z

Conroy, M. J., Durand, A., Lupo, D., Li, X.-D., Bullough, P. A., Winkler, F. K., et al. (2007). The crystal structure of the Escherichia coli AmtB-GlnK complex reveals how GlnK regulates the ammonia channel. Proc. Natl. Acad. Sci. U.S.A. 104, 1213-1218. doi: 10.1073/pnas.0610348104

Curatti, L., Brown, C. S., Ludden, P. W., and Rubio, L. M. (2005). Genes required for rapid expression of nitrogenase activity in Azotobacter vinelandii. Proc. Natl. Acad. Sci. U.S.A. 102, 6291-6296. doi: 10.1073/pnas.0501216102

Diamond, S., Andeer, P. F., Li, Z., Crits-Christoph, A., Burstein, D., Anantharaman, K., et al. (2019). Mediterranean grassland soil C-N compound turnover is dependent on rainfall and depth, and is mediated by genomically divergent microorganisms. Nat. Microbiol. 4, 1356-1367. doi: 10.1038/s41564-019$0449-\mathrm{y}$

Eichorst, S. A., Trojan, D., Roux, S., Herbold, C., Rattei, T., and Woebken, D. (2018). Genomic insights into the Acidobacteria reveal strategies for their success in terrestrial environments. Environ. Microbiol. 20, 1041-1063. doi: 10.1111/1462-2920.14043

Farnelid, H., Bentzon-Tilia, M., Andersson, A. F., Bertilsson, S., Jost, G., Labrenz, M., et al. (2013). Active nitrogen-fixing heterotrophic bacteria at and below the chemocline of the central Baltic Sea. ISME J. 7, 1413-1423. doi: 10.1038/ismej. 2013.26

Fay, P. (1992). Oxygen relations of nitrogen fixation in cyanobacteria. Microbiol. Rev. 56, 340-373. doi: 10.1128/mmbr.56.2.340-373.1992

Fernandez, L., Bertilsson, S., and Peura, S. (2019). Non-cyanobacterial diazotrophs dominate nitrogen-fixing communities in permafrost thaw ponds. Limnol. Oceanogr. 65, S180-S193. doi: 10.1002/lno.11243

Fernandez, L., Mercader, J. M., Planas-Fèlix, M., and Torrents, D. (2014). Adaptation to environmental factors shapes the organization of regulatory regions in microbial communities. BMC Genomics 15:877. doi: 10.1186/14712164-15-877

Finn, R. D., Bateman, A., Clements, J., Coggill, P., Eberhardt, R. Y., Eddy, S. R., et al. (2014). Pfam: the protein families database. Nucleic Acids Res. 42, D222-D230. doi: 10.1093/nar/gkt1223

Gradoville, M. R., Bombar, D., Crump, B. C., Letelier, R. M., Zehr, J. P., and White, A. E. (2017). Diversity and activity of nitrogen-fixing communities across ocean basins. Limnol. Oceanogr. 62, 1895-1909. doi: 10.1002/lno.10542

Grigoriev, I. V., Nordberg, H., Shabalov, I., Aerts, A., Cantor, M., Goodstein, D., et al. (2011). The genome portal of the department of energy joint genome institute. Nucleic Acids Res. 42, D26-D31. doi: 10.1093/nar/ gkr947

Halm, H., Musat, N., Lam, P., Langlois, R., Musat, F., Peduzzi, S., et al. (2009). Co-occurrence of denitrification and nitrogen fixation in a meromictic lake, Lake Cadagno (Switzerland). Environ. Microbiol. 11, 1945-1958. doi: 10.1111/ j.1462-2920.2009.01917.x

He, S., Lau, M. P., Linz, A. M., Roden, E. E., and McMahon, K. D. (2019). Extracellular electron transfer may be an overlooked contribution to pelagic respiration in humic-rich freshwater lakes. mSphere 4:e00436-18. doi: 10.1128/ msphere.00436-18

Heinz, S., Liauw, P., Nickelsen, J., and Nowaczyk, M. (2016). Analysis of photosystem II biogenesis in cyanobacteria. Biochim. Biophys. Acta Bioenerget. 1857, 274-287. doi: 10.1016/j.bbabio.2015.11.007
Howarth, R. W., Marino, R., Lane, J., and Cole, J. J. (1988). Nitrogen fixation in freshwater, estuarine, and marine ecosystems. 1. Rates and importance. Limnol. Oceanogr. 33, 669-687. doi: 10.4319/lo.1988.33.4part2.0669

Hsu, S.-F., and Buckley, D. H. (2009). Evidence for the functional significance of diazotroph community structure in soil. ISME J. 3, 124-136. doi: 10.1038/ismej. 2008.82

Imperial, J., Ugalde, R. A., Shah, V. K., and Brill, W. J. (1985). Mol- mutants of Klebsiella pneumoniae requiring high levels of molybdate for nitrogenase activity. J. Bacteriol. 163, 1285-1287. doi: 10.1128/jb.163.3.1285-1287.1985

Kanehisa, M., Sato, Y., Kawashima, M., Furumichi, M., and Tanabe, M. (2016). KEGG as a reference resource for gene and protein annotation. Nucleic Acids Res. 44, D457-D462. doi: 10.1093/nar/gkv1070

Kang, D. D., Froula, J., Egan, R., and Wang, Z. (2015). MetaBAT, an efficient tool for accurately reconstructing single genomes from complex microbial communities. PeerJ 3:e1165. doi: 10.7717/peerj.1165

Kessler, P. S., Daniel, C., and Leigh, J. A. (2001). Ammonia switch-off of nitrogen fixation in the methanogenic archaeon Methanococcus maripaludis: mechanistic features and requirement for the novel $G \ln B$ homologues, NifI1 and Nifl2. J. Bacteriol. 183, 882-889. doi: 10.1128/JB.183.3.882-889. 2001

Kontur, W. S., Ziegelhoffer, E. C., Spero, M. A., Imam, S., Noguera, D. R., and Donohue, T. J. (2011). Pathways involved in reductant distribution during photobiological H 2 production by Rhodobacter sphaeroides. Appl. Environ. Microbiol. 77, 7425-7429. doi: 10.1128/AEM.05273-11

Letunic, I., and Bork, P. (2016). Interactive tree of life (iTOL) v3: an online tool for the display and annotation of phylogenetic and other trees. Nucleic Acids Res. 44, W242-W245.

Linz, A. M., Crary, B. C., Shade, A., Owens, S., Gilbert, J. A., Knight, R., et al. (2017). Bacterial community composition and dynamics spanning five years in freshwater bog lakes. mSphere 2:e00169-17. doi: 10.1128/mSphere.00 169-17

Linz, A. M., He, S., Stevens, S. L. R., Anantharaman, K., Rohwer, R. R., Malmstrom, R. R., et al. (2018). Freshwater carbon and nutrient cycles revealed through reconstructed population genomes. PeerJ 6:e6075. doi: 10.7717/peerj.6075

Madigan, M. T. (2014). Brock Biology of Microorganisms, 14th Edn, London: Pearson, doi: 10.1007/s13398-014-0173-7.2

Martinez-Argudo, I., Little, R., Shearer, N., Johnson, P., and Dixon, R. (2004). The NifL-NifA system: a multidomain transcriptional regulatory complex that integrates environmental signals. J. Bacteriol. 186, 601-610. doi: 10.1128/JB.186. 3.601-610.2004

Martiny, A. C., Vrugt, J. A., and Lomas, M. W. (2014). Concentrations and ratios of particulate organic carbon, nitrogen, and phosphorus in the global ocean. Sci. Data 1:140048. doi: 10.1038/sdata.2014.48

Müller, A. L., Kjeldsen, K. U., Rattei, T., Pester, M., and Loy, A. (2015). Phylogenetic and environmental diversity of DsrAB-type dissimilatory (bi)sulfite reductases. ISME J. 9, 1152-1165. doi: 10.1038/ismej.2014.208

Muyzer, G., and Stams, A. J. M. (2008). The ecology and biotechnology of sulphatereducing bacteria. Nat. Rev. Microbiol. 6, 441-454. doi: 10.1038/nrmicro 1892

Nordlund, S., and Ludden, P. W. (2006). "Post-translational regulation of nitrogenase in photosynthetic bacteria," in Genetics and Regulation of Nitrogen Fixation in Free-Living Bacteria, eds W. Klipp, B. Masepohl, J. R. Gallon, and W. E. Newton (Dordrecht: Springer), doi: 10.1007/1-4020-2179-8_8

Oetjen, J., and Reinhold-Hurek, B. (2009). Characterization of the DraT/DraG system for posttranslational regulation of nitrogenase in the endophytic betaproteobacterium Azoarcus sp. strain BH72. J. Bacteriol. 191, 3726-3735. doi: $10.1128 /$ jb.01720-08

Oostergetel, G. T., van Amerongen, H., and Boekema, E. J. (2010). The chlorosome: a prototype for efficient light harvesting in photosynthesis. Photosynth. Res. 104, 245-255. doi: 10.1007/s11120-010-9533-0

Parro, V., Puente-Sánchez, F., Cabrol, N. A., Gallardo-Cardeno, I., MorenoPaz, M., Blanco, Y., et al. (2017). Microbiology and nitrogen cycle in the benthic sediments of a glacial oligotrophic deep andean lake as analog of ancient martian lake beds. Front. Microbiol. 10:e929. doi: 10.3389/fmicb.2019. 00929

Pereira, I. A. C., Ramos, A. R., Grein, F., Marques, M. C., Da Silva, S. M., and Venceslau, S. S. (2011). A comparative genomic analysis of energy metabolism 
in sulfate reducing bacteria and archaea. Front. Microbiol. 2:69. doi: 10.3389/ fmicb.2011.00069

Pšenčik, J., Butcher, S. J., and Tuma, R. (2014). "Chlorosomes: structure, function and assembly," in The Structural Basis of Biological Energy Generation, ed. M. Hohmann-Marriott (Dordrecht: Springer), 77-109. doi: 10.1007/978-94-0178742-0_5

R Core Team (2016). R: A Language and Environment for Statistical Computing. Vienna: R Core Team.

Rubio, L. M., and Ludden, P. W. (2008). Biosynthesis of the iron-molybdenum cofactor of nitrogenase. Annu. Rev. Microbiol. 62, 93-111. doi: 10.1146/ annurev.micro.62.081307.162737

Sarkar, A., Köhler, J., Hurek, T., and Reinhold-Hurek, B. (2012). A novel regulatory role of the Rnf complex of Azoarcus sp. strain BH72. Mol. Microbiol. 83, 408-422. doi: 10.1111/j.1365-2958.2011.07940.x

Segata, N., Börnigen, D., Morgan, X. C., and Huttenhower, C. (2013). PhyloPhlAn is a new method for improved phylogenetic and taxonomic placement of microbes. Nat. Commun. 4:2304. doi: 10.1038/ncomms3304

Sperotto, R. A., Gross, J., Vedoy, C., Passaglia, L. M. P., and Schrank, I. S. (2004). The electron transfer flavoprotein fixABCX gene products from Azospirillum brasilense show a NifA-dependent promoter regulation. Curr. Microbiol. 49, 267-273. doi: 10.1007/s00284-004-4318-3

Sullivan, M. J., Petty, N. K., and Beatson, S. A. (2011). Easyfig: a genome comparison visualizer. Bioinformatics 27, 1009-1010. doi: 10.1093/bio informatics/btr039

Thompson, K. J., Simister, R. L., Hahn, A. S., Hallam, S. J., and Crowe, S. A. (2017). Nutrient acquisition and metabolic potential of photoferrotrophic Chlorobi. Front. Microbiol. 8:e1212. doi: 10.3389/fmicb.2019.001212

Tremblay, P.-L., Zhang, T., Dar, S. A., Leang, C., and Lovley, D. R. (2013). The Rnf complex of Clostridium ljungdahlii is a proton-translocating ferredoxin: NAD+ oxidoreductase essential for autotrophic growth. mBio 4:e00406-12.

Watras, C., Morrison, K., Lottig, N., and Kratz, T. (2015). Comparing the diel cycles of dissolved organic matter fluorescence in a clear-water and two dark-water Wisconsin lakes: potential insights into lake metabolism. Can. J. Fish. Aquat. Sci. 73:150903143454004. doi: 10.1139/cjfas-2015-0172
Wickham, H. (2009). Ggplot2: Elegant Graphics for Data Analysis. New York, NY: Springer-Verlag.

Xie, J.-B., Du, Z., Bai, L., Tian, C., Zhang, Y., Xie, J.-Y., et al. (2014). Comparative genomic analysis of N2-fixing and non-N2-fixing Paenibacillus spp.: organization, evolution and expression of the nitrogen fixation genes. PLoS Genet. 10:e1004231. doi: 10.1371/journal.pgen.10 04231

Xiong, J., Fischer, W. M., Inoue, K., Nakahara, M., and Bauer, C. E. (2000). Molecular evidence for the early evolution of photosynthesis. Science 289, 1724-1730. doi: 10.1126/science.289.5485.1724

Zani, S., Mellon, M. T., Collier, J. L., and Zehr, J. P. (2000). Expression of nifH genes in natural microbial assemblages in Lake George, New York, detected by reverse transcriptase PCR. Appl. Environ. Microbiol. 66, 3119-3124. doi: 10.1128/AEM.66.7.3119-3124.2000

Zheng, Y., Harris, D. F., Yu, Z., Fu, Y., Poudel, S., Ledbetter, R. N., et al. (2018). A pathway for biological methane production using bacterial irononly nitrogenase. Nat. Microbiol. 3, 281-286. doi: 10.1038/s41564-0170091-5

Zhuang, W.-Q., Yi, S., Bill, M., Brisson, V. L., Feng, X., Men, Y., et al. (2014). Incomplete Wood-Ljungdahl pathway facilitates one-carbon metabolism in organohalide-respiring Dehalococcoides mccartyi. Proc. Natl. Acad. Sci. U.S.A. 111, 6419-6424. doi: 10.1073/pnas.1321542111

Conflict of Interest: The authors declare that the research was conducted in the absence of any commercial or financial relationships that could be construed as a potential conflict of interest.

Copyright (c) 2020 Fernandez, Peura, Eiler, Linz, McMahon and Bertilsson. This is an open-access article distributed under the terms of the Creative Commons Attribution License (CC BY). The use, distribution or reproduction in other forums is permitted, provided the original author(s) and the copyright owner(s) are credited and that the original publication in this journal is cited, in accordance with accepted academic practice. No use, distribution or reproduction is permitted which does not comply with these terms. 